\title{
Child Protect: Response to Poverty Alleviation in the Philippine Indigenous Community
}

\author{
Noemi Cabaddu, MSW \\ St. Paul University Philippines \\ Mabini Street, Tuguegarao City \\ Philippines
}

\begin{abstract}
This study is about the Child Protection Towards Enabling Childhood Development and Community Transformation, also known as Child ProTECT, aimed to help uplift the lives of the poor indigenous peoples and the children residing in Apayao, Philippines. The SPUP-CDCFI partnered with ChildFund Philippines in the implementation of the projects of Child ProTECT through trainings on maternal health and child care, nutrition and sanitation, education and formation, livelihood and skills, and community development. The impact and benefits to the participants of Child ProTECT were assessed. In a way, the program contributed in the thrust of poverty alleviation and improving the lives of the indigenous people.
\end{abstract}

Keywords: indigenous people, poverty alleviation, child protection

\section{Introduction}

The indigenous people are considered as among the poorest sectors of society who typically have low earning capacity and limited access to health services and education. Based on national survey data from ten countries in Latin America, Asia, and Africa, it was shown that the indigenous populations in every country account for those who are poor and struggling due to insecure land and property rights, discrimination, heightened vulnerability to risk and climate change, and a wide range of health, education and other related socio-economic disparities. It is estimated that about 370 million indigenous people in the world are in over 90 countries, the "indigenous communities represent about $5 \%$ of the world's population but make up $15 \%$ of the world's extreme poor..."(Patrinos, H.A.,2017; Hall and Gandolfo, 2016; Hall, G. and Patrinos, H.A.,2014). This worldwide poverty of indigenous people are addressed in terms of policy initiatives, development projects and networking with the public and private agencies and organizations (Wien, F., 2017; Joseph B., 2013; Tapscott, D., 2013)

In the Philippines, the indigenous peoples are among the poorest and most disadvantaged in the country. Many of them are struggling and facing discrimination, exclusion in areas such as access to land, healthcare, education, and political participation (Chadron, R., 2018; Torres, L., 2016; FIAN, 2014; Eder, J., 2013, Ty, R., 2010). Culled from the report of the United Nations Development Programme (UNDP, 2013), the Philippines is described as a "culturally diverse country with an estimated 14-17 million Indigenous Peoples (IPs) belonging to 110 ethno-linguistic groups. They are mainly concentrated in Northern Luzon (Cordillera Administrative Region, 33\%) and Mindanao (61\%), with some groups in the Visayas area. The Philippine Constitution, in recognition of this diversity and under the framework of national unity and development, mandates state recognition, protection, promotion, and fulfillment of the rights of Indigenous Peoples. Further, Republic Act 8371, also known as the "Indigenous Peoples Rights Act" (1997, IPRA), recognized the right of IPs to manage their ancestral domains; it has become the cornerstone of current national policy on IPs". St. Paul University Philippines (SPUP), an autonomous university situated in Tuguegarao City, Philippines, has a strong holistic thrust towards academic excellence, spirituality and value formation, and social responsibility. Likewise, the university has extensive community outreach projects which include development projects for the poor and indigenous people in the province of Apayao, Cagayan. SPUP Community Development Center Foundation, Inc. (SPUP-CDCFI), the social service arm of SPUP, is duly licensed, registered and granted accreditation by the Department of Social Welfare and Development (DSWD) Standards Bureau as a Social Welfare and Development Agency (SWDA). The SPUP-CDCFI programs and projects are aimed to promote the integral human development of the people who are poor and marginalized, especially the rural poor and the indigenous people, in order to alleviate their causes through trainings, education and formation programs. The children are the most vulnerable to suffer the deprivation and malnutrition caused by poverty. In its desire to help uplift the lives of the indigenous peoples and the children of Apayao, SPUP-CDCFI partnered with ChildFund International, a prominent child-focused organization, whose mission is to help deprived, excluded and vulnerable children improve their lives and have the opportunity to become young adults, parents and leaders. (SPUP-CDCFI Brochure, 2017). 
Apayao is targeted for this study as it is inhabited with Indigenous People (IP) who are the most marginalized groups in the Philippines. Apayao is home to the Igorot tribe and the Isnags claim that they are the ethnic group that are dominant in the province.

Sr. Merceditas Ang, SPC, the SPUP President and Chairperson of SPUP-CDCFI, and Mr. Federico Diaz-Albertini, the Country Director of ChildFund Philippines, entered into a collaborative agreement to implement the "Child Protection Towards Enabling Childhood Development and Community Transformation," also known as "Child ProTECT" for the program participants of the Province of Apayao, particularly, the Municipalities of Luna and Flora. The Child ProTECT was launched in Luna, Apayao, on Nov. 24, 2017. This community development project is geared towards child protection towards enabling childhood development and community transformation of the Indigenous People (IP) in the identified locality (Cabaddu, N., 2018). Child ProTECT is one among the many ways of how the SPUP is carrying out its mission of uplifting the quality of life and effecting social transformation. This program is not only undertaken as a function but as a mission as well. It is hoped that through this partnership SPUP-CDCFI will be able to contribute to the government's thrust of poverty alleviation and improving the lives of our indigenous peoples.

\section{Statement of Purpose}

This is a descriptive study of the Child ProTECT Program. Specifically, the following are the objectives of the study:

1. Identify the aims, projects and the extent of implementation of Child ProTECT;

2. Determine the enablers and barriers in the implementation of the Child ProTECT Program; and

3. Evaluate the perceived impact and benefits of the Child ProTECT Program to the participants and beneficiaries, in terms of poverty alleviation to the indigenous community.

\section{Methodology}

The study made use of documentary analysis of the reports and brochures of the SPUP-CDCFI, field observation, survey, interview, and focus group discussion. Questionnaires were administered to a sample of the beneficiaries and implementers. The respondents were also interviewed regarding the impact of the program and were asked recommendations to improve operations and accomplishment.

\section{Scope and Limitations of the Study}

The study covers the period from January 31 to May 30, 2018 involving about 350 indigenous families, local government units, national line agencies and the stakeholders in gathering data from 20 barangays of the municipalities of Luna and Flora, Province of Apayao in the Philippines. The respondents were family members of children 3-5 years of age, and have resided in the community of indigenous people in Apayao for at least 10 years to ensure that they are knowledgeable. The researcher encountered difficulty in gathering data due to limited available data from respondents and stakeholders. Also, the rainy season and the mountain terrain posed accessibility and mobility limitation.

\section{Results and Discussion}

The results were based on the data gathered during field visits, survey and interview with the participants and beneficiaries. Apayao is known to be an agricultural province in the Philippines which is frequently affected by natural calamities such as typhoons, flood and drought. The poor indigenous peoples (IPs) and the landless farming families in Apayao are the ones greatly affected by these calamities. Poverty, lack of information and inaccessibility are the main factors that degrade health and sanitation of the IP families. There were problems on availability of safe and potable water, inadequate facilities and manpower for health services, lack of sanitary facilities, lack of information for waste management, high practice of conventional farming using hazardous chemicals, yearly typhoon attacks and the occurrence of diseases during the long season of rain. The data on the profile of the indigenous families in Apayao as shown in Figure 1, were taken from the Apayao Statistical Data and Wikipedia. 
Figure 1. Demographic Profile of Indigenous Families in Apayao

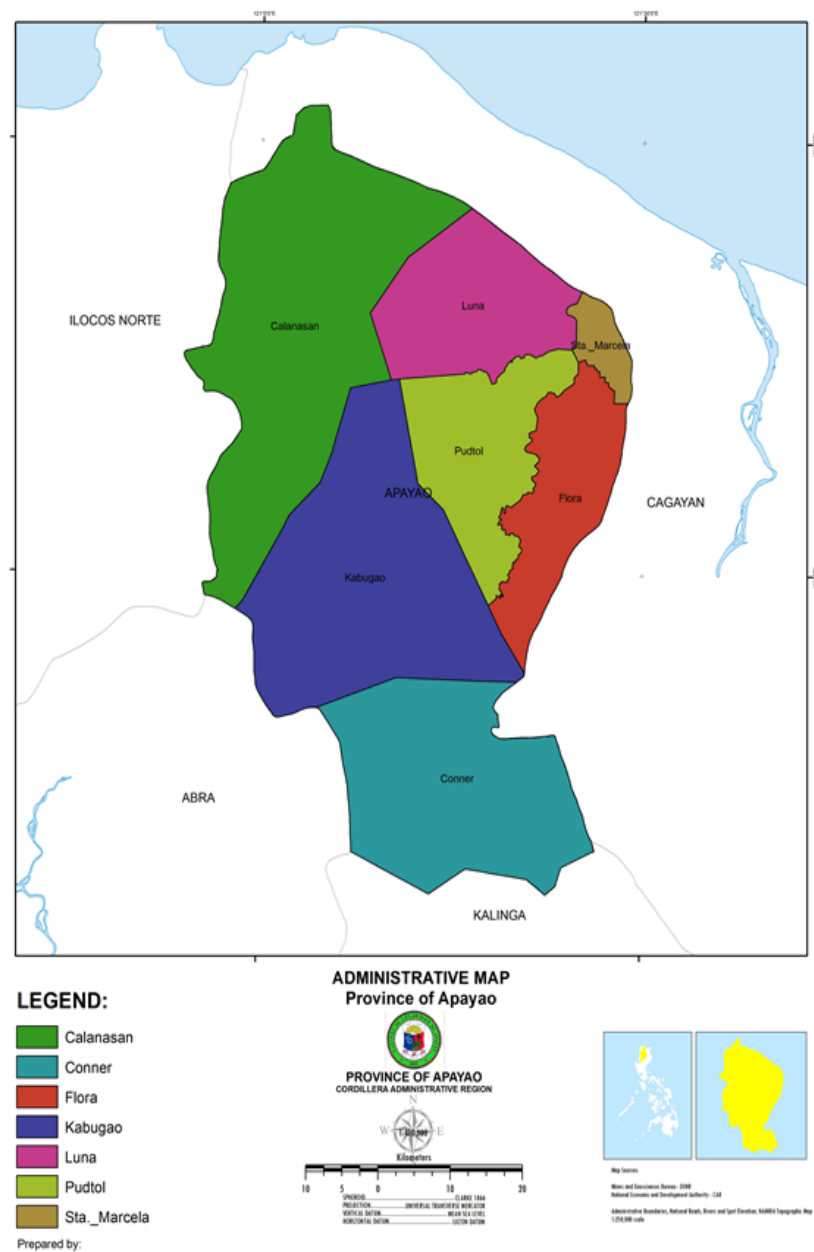

\begin{tabular}{|l|}
\hline \\
Area: $\mathbf{4 , 4 1 3 . 3 5}$ square kilometers \\
Population: $\mathbf{1 1 9 , 1 8 4}$ \\
Households: $\mathbf{2 4 , 4 4 8}$ \\
Poverty Incidence: $\mathbf{3 0 . 9 8 \%}$ \\
Poverty Threshold: PhP10,469.00 \\
Unemployment rate: $\mathbf{2 . 1 4 1}$ \\
Hh w/Income below Poverty Threshold: $\mathbf{1 3 , 1 7 0}$ \\
Hh w/out access to Water Supply: $\mathbf{8 , 4 7 1}$ \\
Hh w/out access to Sanitation: $\mathbf{4 , 3 7 5}$ \\
Hh living in makeshift housing: $\mathbf{4 1 5}$ \\
Hh who are informal settlers: $\mathbf{1 , 5 8 9}$ \\
Children under 1: $\mathbf{2 , 1 8 6}$ \\
Infant Mortality Rate: $\mathbf{1 0 4}$ \\
Children Under 5: $\mathbf{1 2 , 2 9 2}$ \\
Malnourished: $\mathbf{3 7 8}$ \\
who died: $\mathbf{5 4}$ \\
Pregnancy related death: $\mathbf{6}$ \\
6-15 yrs. old not attending school: $\mathbf{6 , 5 8 6}$ \\
Victims of Crime: $\mathbf{1 1 5}$ \\
Major Industry: Agriculture \\
\end{tabular}

Table 1. Estimated household monthly income according to the research survey

\begin{tabular}{|l|l|l|l|l|}
\hline \multicolumn{2}{|l|}{ LUNA } & FLORA & \% \\
\hline Monthly Income & Number & \% & Number & $72.50 \%$ \\
\hline 5,000 and Below & 101 & $61.59 \%$ & 87 & $21.67 \%$ \\
\hline $5,001-10,000$ & 50 & $30.49 \%$ & 26 & $5.83 \%$ \\
\hline $10,001-15,000$ & 7 & $4.27 \%$ & 7 & \\
\hline $15,001-20,000$ & 2 & $1.22 \%$ & & \\
\hline $20,001-30,000$ & 4 & $2.44 \%$ & & \\
\hline $30,001-40,000$ & & & & \\
\hline $40,001-50,000$ & & & & $\mathbf{1 0 0 \%}$ \\
\hline ABOVE-50,000 & & & & $\mathbf{1 2 0}$ \\
\hline Total & $\mathbf{1 6 4}$ & $\mathbf{1 0 0 \%}$ & & \\
\hline
\end{tabular}

As shown in the Table 1, most of the IP participants said they have an estimated monthly income of below Ph5,000. Most of those who participated are living below the poverty threshold. In the respondents of Luna and Flora, 92\% and $94 \%$, respectively, are below the poverty threshold.

\section{Child ProTECT}

Child ProTECT is geared towards child protection towards enabling childhood development and community transformation for the municipalities of Luna and Flora in Apayao. It is carried out by Ensuring Nutrition, Health, and Children's Education (ENHANCE) and Family-Based Disaster Risk Management (FDRM) and Child Protection in Emergencies. Initially, the project was designed for 1, 200 indigenous children enrolled in the project. During the implementation the beneficiaries were increased to 4,000 . 
The target group of Child ProTECT are children aged 3-5 years old and their families from indigenous communities who are considered indigenous peoples (IPs), marginalized since time immemorial. These children are poor and especially affected because they are dependent for their survival on adults. Infants and young children of indigenous families in Apayao are among the most vulnerable of the populations. They face many challenges such as discrimination and neglect that hinder them from developing into fully functioning adults in the community. These children residing in Apayao do not have access to quality early childhood care, health and nutrition. This is due to the lack of proper infrastructure, lack of qualified teachers, shortage of adequate learning materials and accessibility among others. The areas selected for the project suffer from poor quality health services and access to basic education and learning facilities, affecting young infants and children. To roll-out and implement the Child ProTECT, the researcher together with the staff of the SPUP-CDCFI in partnership with ChildFund Philippines, have conducted the following training sessions from November 2017 to May 2018 (Cabaddu, N., 2018):

1. Parents/Caregivers Session on Hygiene and Childhood Illnesses and Proper Nutrition

2. Parents' Sessions on Health, Nutrition and Responsive Care This training was aimed at imparting knowledge, attitude and skills to parents and caregivers which is needed to ensure that children are healthy and secure.

3. Training of Parents/Caregivers Session on Family-Based Disaster Risk Management (FDRM) and Child Protection in Emergencies The Family-Based DRM Roll-out training was conducted for the 12 Child ProTECT covered barangays from the Municipality of Flora Apayao. After attending the training, the enrolled families were educated and equipped with knowledge and competencies pertaining FDRM.

4. Volunteers' Training on Sponsorship Management The 2-day Paulinian Volunteers Training was aimed at introducing the systems and procedures in the management of child sponsorship and in the conduct of the Annual Child Verification Process. The trained volunteers served during the conduct of Child Verification System (CVS) in all 1,200 enrolled children for Child Protect Sponsorship Management.

5. Volunteers Training on ChildProTECT and Sponsorship Management with Child Verification Process The 3-day volunteers training was aimed at introducing the systems and procedures in the management of child sponsorship of SPUP-CDCFI's Child ProTECT Project in partnership with ChildFund Philippines.

\section{Extent of Implementation of Projects}

The training sessions and intervention activities equipped the participants with relevant knowledge regarding health and childcare, disaster risk and development. Table 2 illustrates the summary of the extent of the projects accomplished within the Child ProTECT program. As indicated in the status, all the proposed projects have been completed. Additionally, the budget breakdown was indicated. This shows the compliance of the institution for the complete transparency of budget allocation. The source of funding are: 1) subsidy from St. Paul University Philippines (Annual Budget for Community Extension); 2) grants from ChildFund Philippines; and 3) donations from private individuals, and Non-Government Organizations. 
Table 2. Accomplishment of Projects

\begin{tabular}{|c|c|c|c|}
\hline Projects & Costs & Beneficiaries & Status \\
\hline $\begin{array}{l}\text { Distribution of } 87 \text { bicycles for children } \\
\text { (means of transportation for parents to bring } \\
\text { children to school in Luna, Apayao) }\end{array}$ & Php171,000.00 & $\begin{array}{l}87 \text { sponsored children ages } 5-9 \\
\text { years old from the municipality of } \\
\text { Luna, Apayao }\end{array}$ & Completed \\
\hline Distribution of native chicken & Php174,600.00 & $\begin{array}{l}\text { Sponsored families in the } \\
\text { municipality of Flora, Apayao }\end{array}$ & Completed \\
\hline Distribution of goats & Php168, 000.00 & $\begin{array}{l}35 \text { sponsored families in the } \\
\text { municipality of Flora, Apayao }\end{array}$ & Completed \\
\hline Installation of 5-units Hand Pump Wells & Php174,000.00 & $\begin{array}{l}\text { Installed in } 5 \text { Child Development } \\
\text { Centers in the municipalities of } \\
\text { Luna and Flora, Apayao }\end{array}$ & Completed \\
\hline Installation of Water Harvesting/Catcher & Php99,580.44 & $\begin{array}{l}7 \text { families in the municipality of } \\
\text { Flora, Apayao }\end{array}$ & Completed \\
\hline $\begin{array}{l}\text { Installation of Water Facilities in Child } \\
\text { Development Centers }\end{array}$ & Php120,000.00 & $\begin{array}{l}\text { Municipalities of Luna and Flora, } \\
\text { Apayao }\end{array}$ & Completed \\
\hline Distribution of 30 pieces mosquito nets & Php $10,500.00$ & $\begin{array}{l}30 \text { families in the municipality of } \\
\text { Flora, Apayao }\end{array}$ & Completed \\
\hline Distribution of 120 Hygiene Kits & 000.00 & $\begin{array}{l}120 \text { enrolled children in the } \\
\text { municipalities of Luna and Flora, } \\
\text { Apayao }\end{array}$ & leted \\
\hline $\begin{array}{l}\text { Translation of Modules into Isnag and Aggay } \\
\text { Versions (Mother Tongue) }\end{array}$ & Php300,000.00 & $\begin{array}{l}\text { Children ages } 3-5 \text { years old in the } \\
\text { municipalities of Luna and Flora, } \\
\text { Apayao }\end{array}$ & Completed \\
\hline Training of Facilitators & Php105,000.00 & $\begin{array}{l}\text { Facilitators in the municipalities of } \\
\text { Luna and Flora, Apayao }\end{array}$ & Completed \\
\hline $\begin{array}{l}\text { Roll-out Training of Family-based Disaster and } \\
\text { Risk Management (FDRM) and Emergency } \\
\text { Preparedness, and Child Protection in } \\
\text { Emergencies (CPiE) }\end{array}$ & Php398,330.00 & $\begin{array}{l}1,200 \text { enrolled families in the } \\
\text { municipalities of Luna and Flora, } \\
\text { Apayao }\end{array}$ & Completed \\
\hline 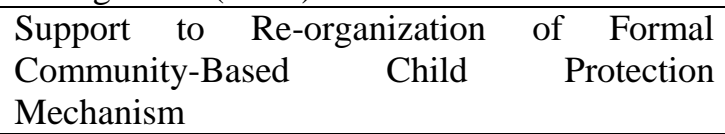 & Php13,000.00 & $\begin{array}{l}\text { Members in the Municipalities of } \\
\text { Luna and Flora, Apayao }\end{array}$ & Completed \\
\hline
\end{tabular}

\section{Enablers and Barriers for Program implementation}

The main enabler of the program, together with key organizations, is St. Paul University Philippines. The SPUP Community Development Center Foundation, Inc. (SPUP-CDCFI) provides opportunities for students and employees to involve themselves in community service and to carry out the mission of Jesus Christ in proclaiming the gospel to the depressed, deprived and underserved communities. This mission is intended to empower the partner communities and have the following objectives (SPUP-CDCFI Brochure, 2017):

1. To promote the integral human development of the people who are poor and marginalized, especially the indigenous peoples in order to alleviate their causes through trainings, education and formation programs.

2. To provide opportunities for people in need to improve the quality of their lives through efficient and effective management of resources.

3. To conduct livelihood training activities, non-formal education projects and scholarship assistance.

4. To provide scholarships and opportunities to poor farmers and their children, indigenous people and survivors of calamities;

ChildFund Philippines is another enabler of the Child ProTECT Program. It provided financial support, monitoring staff, and automated system and process for the efficient implementation of the projects. Likewise, the Department of Social Welfare and Development (DSWD), the local chief executives of the municipalities of Luna and Flora, and other local government officials have extended invaluable assistance.The challenges and barriers encountered by the program personnel include the following: a) distance of the settlement of the indigenous peoples' community; b) difficulty to travel back and forth as most roadways or terrains going to these communities are still underdeveloped; c) minimal assistance from barangay officials; and d) lack of communication skills of many indigenous people who can only speak their native dialect. 
Despite development initiatives and efforts for the Indigenous Peoples and their children, they remain as part of the disadvantaged, excluded and vulnerable (DEV) populations. Children in particular, continuously encounter pressing issues like deprivation of basic needs such as food, access to health, education services, discrimination in school and community activities, and violation of human rights. Indigenous peoples' sensitive marginalization is closely connected to a number of interlinking factors, such as poverty, ethnicity (social stigma and institutionalized discrimination), language barriers, gender-based discrimination, traditional practices (including early marriage), and lack of access to basic services due to their geographical isolation.

\section{Benefits of the Child ProTECT Program}

The perceived impact of the Child ProTECT to the participants and beneficiaries is positive. The participants are grateful for the trainings and projects that have been completed. They are happy about the water wells, community health centers, classrooms, and the multi-purpose hall built. The local IP residents are enjoying the use of such facilities. Awareness and understanding about maternal health, child-rearing practices, child protection and development, nutrition and sanitation, family life, social welfare and development in the community had increased. The functional literacy and social skills of the beneficiaries have improved. The livelihood training and farming skills have taught the parents to work for their living and earn income for their families. Moreover, the participants learned to save and protect their lives and properties during calamities, through the training on Family-based Disaster Risk Management. Implementers, on the other hand, have considered the experiences as great contributor for personal growth. At first, projects are seen as big challenges and they were afraid that the goals will not be met. However, the SPUP-CDCFI have duly managed and guided the personnel which led to the success of the program. In a way, the participants considered the Child ProTECT as a great help in improving the social and economic status of the indigenous peoples in the municipalities of Luna and Flora in the province of Apayao. The parents and caregivers have improved in earning capacity and work skills, child-rearing practices, and spending habits.

The Child ProTECT is new and barely two years of implementation, and the study conducted is for a short time frame, hence, the effect on poverty alleviation is only beginning to trickle and dawn upon the beneficiaries. Although the participants are still considered as materially poor, but there is change and transformation in their work orientation and practices, openness to education and social aspirations, and positive outlooks in life despite hardships.

\section{Conclusion and Recommendation}

The Child ProTECT Program was efficiently implemented, and its impact has been positive in the community of indigenous people in the municipalities of Luna and Flora in the province of Apayao, Philippines. Child ProTECT was responsive to the needs and concerns of the IPs, particularly on poverty and lack of access to maternal and child healthcare. It is highly extensive in terms of relevance, efficiency, effectiveness and sustainability both in the observed changes in the target community and the perspective of the participants. Therefore, it is highly recommended that SPUP-CDCFI continue its partnership with ChildFund Philippines and implement the projects in the other municipalities of Apayao. Moreover, the continuing monitoring, feedbacking and evaluation of Child ProTECT is recommended.

\section{References}

Apayao Statistical Data CY 2015. Retrieved from: rssocar.psa.gov.ph/poverty/First\%20Semester\%202015\%2 $0 \% 20$ Poverty\%20Statistics

Apayao Wikipedia. Retrieved from: https://en.wikipedia.org/wiki/Apayao

Cabaddu, N. (2018). Annual report on the Child ProTECT Program

Chadron, R. (2018). Driven from home, Philippine indigenous people long for their land. Posted on April 19, 2018. Retrieved from: https://news.abs-cbn.com/focus/04/19/18/driven- from-home-philippine-indigenous-peoplelong-for-their-land

Eder, J. (2013). The Future of Indigenous Peoples in the Philippines: Sources of Cohesion, Forms of Difference. Philippine Quarterly of Culture and Society . Vol. 41, No. 3/4 (September/December 2013), pp. 273-294.

FIAN Philippines (2014). Indigenous peoples. Post from the Food First Information \& Action Network (FIAN) Philippines. Retrieved from: |http://www.fianphilippines.org/ issues/indigenous-peoples/

Hall, G. and Gandolfo, A. (2016). Poverty and exclusion among indigenous peoples: The global evidence. Voices. August 9, 2016. Retrieved from: blogs.worldbank.org/voices/poverty-and-exclusion-among-indigenouspeoples-global-evidence

Hall, G. and Patrinos, H.A., eds. (2014). Indigenous peoples, poverty, and development. Cambridge University Press. New York, U.S.A. 
Joseph, B., CEO (2013). 7 basic solutions for barriers to aboriginal employment. Indigenous Corporate Training Inc. Retrieved frm : https://www.ictinc.ca/7-basic-solutions-barriers-to-aboriginal-employment

Patrinos, H.A. (2017). Indigenous peoples, poverty and the search for solutions. HuffPost. October 7, 207. Retrieved from: https://hpatrinos.com/2017/10/07/indigenous-peoples-poverty-and-the-search-for-solutions/

SPUP-CDCFI Brochure (2017).

Tapscott, D., (2013). A home-grown solution to First Nations poverty. The Star. November 4, 2013. Retrieved from: https://www.thestar.com/opinion/commentary/2013/11/04/a_homegrown_solution_to_first_nations_poverty.ht $\mathrm{ml}$

Torres, L. (2016). Indigenous peoples in the Philippines: Perspectives on inclusion. Global Observatory for Inclusion. June 15, 2016.

Ty, R. (2010). Indigenous peoples in the Philippines: Continuing struggle. FOCUS. December 2010 Volume 62.

United Nations Development Program (2013). Indigenous peoples in the Philippines. Fast Facts. UNDP Philippines. July 24, 2013. Retrieved from:

http://www.ph.undp.org/content/philippines/en/home/librar y/democratic_governa nce/FastFacts-IPs.html

Wien, F. (2017). Tackling poverty in indigenous communities in Canada. Prince George, BC: National Collaborating Centre for Aboriginal Health. Retrieved from : https://www.ccnsa-nccah.ca/docs/determinants/FS-Tackling Poverty Canada-SDOH- Wien-EN.pdf 